\title{
IMPLICAÇÕES ÉTICO-EPISTEMOLÓGICAS DA NEGOCIAÇÃO NOS PROCESSOS DE AVALIAÇÃO INSTITUCIONAL PARTICIPATIVA
}

\author{
MARA Regina Lemes De SoRd ${ }^{*}$
}

\begin{abstract}
RESUMO: Discute-se a importância de modelos alternativos de regulação da qualidade da escola pública como reação propositiva aos modelos de avaliação centrados nos resultados dos estudantes nos testes padronizados. Dada a escassez de estudos sobre implementação de políticas públicas, toma-se a experiência de uma rede municipal de ensino como referência para a análise das potencialidades e vulnerabilidades do processo de avaliação institucional participativa implementado, tendo como foco as reuniões de negociação entre os gestores do nível central e os atores das escolas. Busca-se identificar concepções de qualidade e de avaliação que regem o processo de negociação e as consequências para o processo decisório. Observa-se que os atores tendem a aprimorar o entendimento de seu papel na negociação e há indícios de ampliação do protagonismo e da implicação dos atores das escolas com a lógica avaliativa do modelo,com a continuidade do processo.
\end{abstract}

Palavras-chave: Regulação da qualidade. Escola pública. Negociação. Avaliação institucional. Políticas públicas.

\section{EPISTEMOLOGICAL ETHICAL IMPLICATIONS OF TRADING IN THE PROCESS OF INSTITUTIONAL PARTICIPATORY EVALUATION}

ABSTRACT: This paper discusses the importance of alternative models of regulation of the quality of public schools in response to the purposeful evaluation models focused on student achievement on standardized tests. Given the paucity of studies on public policy implementation becomes the experience of a municipal school system as a reference for the analysis of the strengths and vulnerabilities of the evaluation process implemented taking as participatory institutional focus on the negotiation meetings between the managers of the central and the actors of the schools. The aim is to identify concepts of quality and assessment governing the negotiation process and the consequences for decision making. It is observed that the actors tend to enhance the understanding of his role in negotiating and there is evidence of expanding the role and involvement of players from schools with the logic evaluation of the model with the continuity of the process.

Key words: Quality regulation. Public school. Negotiation. Institutional evaluation. Public politics. * Doutora em Educação e professora da Faculdade de Educação da Universidade Estadual de Cam-
pinas (Unicamp). E-mail: maradesordi@uol.com.br 


\title{
IMPLICATIONS ETHICO-EPISTEMOLOGIQUES DE LA NEGOCIATION DANS LES PROCESSUS D'EVALUATION INSTITUTIONNELLE PARTICIPATIVE
}

\begin{abstract}
RÉSUMÉ: On discute l'importance de modèles alternatifs de régulation de la qualité de l'école publique comme réaction propositionnelle aux modèles d'évaluation centrés sur les résultats des étudiants aux tests standardisés. Etant donné la rareté des études sur la mise en oeuvre de politiques publiques, on choisit l'expérience d'un réseau municipal d'enseignement comme référence pour l'analyse des potentialités et vulnérabilités du processus d'évaluation institutionnelle participative en vigueur, en prenant comme cible les réunions de négociation entre les gesteurs du niveau central et les acteurs de l'école. On cherche à identifier les conceptions de qualité et d'évaluation qui régissent le processus de négociation et les conséquences pour le processus décisionnaire. On observe que les acteurs tendent à améliorer la compréhension de leur rôle dans la négociation et on trouve des indices d'une amplification du protagonisme et de l'implication des acteurs de l'école dans la logique évaluative du modèle avec la continuité du processus.
\end{abstract}

Mots-clés: Régulation de la qualité. Ecole publique. Négociation. Evaluation institutionnelle. Politiques publiques.

\section{Introdução}

A valiar a qualidade de uma instituição de ensino, sobretudo por meio dos resultados obtidos pelos estudantes nos exames nacionais de desempenho, tem sido a marca das políticas públicas em todos os níveis do sistema educacional e anuncia a adesão a uma concepção reducionista de educação e de avaliação, porém com indiscutível força indutora.

A leitura crítica dos desdobramentos deste processo, dada a onipresença da avaliação na vida das escolas, das pessoas, das nações, não pode ser postergada. Estes desdobramentos requerem atenção, pois as concepções de qualidade a que se filiam não são claramente anunciadas e fazem crer que há consenso sobre estas.

A transformação qualitativa das escolas na direção de um projeto pedagógico socialmente pertinente, gerador de aprendizagens significativas e duradouras, tem sido sumariamente desacelerada quando se tomam, inadvertidamente, as medidas educacionais como expressão maior, quase exclusiva, da qualidade da escola.

Parece-nos oportuno denunciar a precariedade dos resultados de políticas desta natureza na aprendizagem dos estudantes. Isto nos faz refletir sobre os grandes investimentos que são feitos para manter este sistema em funcionamento, sem que resultem em melhorias nas aprendizagens.

Paradoxalmente, este modelo de regulação gera distorções bastante relevantes na organização do trabalho da escola, que elevam também o custo social da 
opção, pois refletem nas aprendizagens, sonegando os estudantes do acesso a tudo aquilo que não é priorizado nos testes padronizados.

Seja pelas implicações nas dinâmicas curriculares que passam a ser orientadas pelo que é abordado nos exames; seja pela padronização de práticas pedagógicas postas em ação pelos professores, visando o treinamento dos estudantes para acertarem as questões do exame; seja pelo prejuízo que acarretam na ruptura com uma cultura de avaliação ranqueadora e meritocrática; seja pelo estímulo a práticas fraudulentas na aplicação das provas ou, ainda, pelo viés do seu alto custo, defendemos a importância de se recuperar o debate sobre uma concepção de qualidade educacional que extrapole aquilo que pode ser objeto de medição nos testes padronizados (Madaus, Russell \& Higgins, 2009; Freitas, 2011; Paro, 2011; Fernandes, 2009).

Não podemos ignorar que a insistência em modelos de avaliação, cuja base é meritocrática e ranqueadora, pode ainda induzir a decisões que discriminam os estudantes, penalizando aqueles que mais precisam da escola, tornando-os invisíveis nos dias dos exames para não prejudicarem o rendimento da turma. Reações a estas distorções, que legitimam a exclusão de estudantes em nome de uma qualidade de ensino artificialmente produzida, requerem proposição de modelos alternativos de avaliação.

Não se desconsidera a necessidade das medidas como um dos componentes da avaliação. Porém, o que justificaria o silenciamento sobre a insuficiência destas informações que expõem o baixo desempenho dos estudantes sem que, paralelamente, se acione uma rede de interpretação e problematização de seus significados? Dias Sobrinho (2010) nos lembra dos riscos da supervalorização das medidas quando estas são transformadas no determinante central no sistema de controle legal-burocrático.

Não há como desconhecer a força com que o discurso sobre a qualidade das escolas tem aflorado na educação básica. Nem surpreende que as políticas sistêmicas de avaliação propostas para este nível de ensino reproduzam tendências hegemônicas no campo avaliatório anteriormente aplicadas em outros níveis de ensino, não sem resistências, é bom que se mencione. As propostas de avaliação externa concentram-se em modelos que priorizam a medição do desempenho dos estudantes em testes estandardizados (Prova Brasil e Saresp), associando os resultados a indicadores ligados às taxas de aprovação e evasão dos alunos, entre outros, que geram índices que explicitam o estágio de cada escola (Ideb e Idesp), em relação a determinadas metas a alcançar em dada fração de tempo. Ainda que esta lógica não coíba ações pelas escolas no âmbito da apropriação crítica dos dados, a cultura de resultados exerce forte pressão sobre as escolas e pode ocasionar distorções já referidas. 
Observa-se que melhoria dos índices não significa necessariamente melhorias que ampliem o horizonte cultural dos alunos. Sequer implicam melhoria nas aprendizagens que os testes procuram reforçar. Este fato é confirmado por pesquisas que sinalizam a precariedade dos resultados obtidos, no que se refere à transformação real do nível de aprendizagem dos estudantes em países cujas políticas públicas foram marcadas pela lógica da distribuição de bônus, da responsabilização unilateral e meritocrática (Madaus, Russell \& Higgins, 2009).

Motivadores externos tendem a enviesar as razões pelas quais se luta por uma escola pública de qualidade. O compromisso ético-político dos profissionais da educação com a qualidade do projeto pedagógico da escola acaba secundarizado.

Mudanças nos cenários educativos dependem de muitos outros fatores que devem ser agregados aos modelos de avaliação, de modo que possam cumprir aquilo que deles se espera, ou seja, o aprimoramento dos projetos pedagógicos pela via do planejamento meticuloso de intervenções que visem à superação das vulnerabilidades e à preservação das potencialidades existentes nas escolas, resultando em maiores e melhores aprendizagens para o conjunto dos estudantes.

Este texto busca examinar o modelo de avaliação institucional implementado como política pública de avaliação em uma rede municipal de ensino, cujo arcabouço ético-epistemológico pode ser entendido como reação propositiva aos modelos de $a c$ countability forte. Sua concepção relocaliza a avaliação no nível das escolas, tomando-as como referência para o processo de qualificação. Compreende o projeto pedagógico como expressão do coletivo da escola, estimulando a participar de sua formulação e avaliação por práticas de gestão democrática. O modelo se ancora na categoria da negociação entre os atores implicados no processo avaliatório, com vistas à formulação de um pacto de qualidade (Bondiolli, 2004; Freitas et al., 2009).

A adoção deste referencial inaugura forma de regulação que se realiza, de modo complementar, entre o centro do sistema e as escolas e seus atores, na perspectiva de construção de uma rede de ensino solidária na promoção das aprendizagens dos estudantes. O diálogo entre diferentes níveis da rede de ensino e diferentes atores sobre o mesmo fenômeno (qualificação da escola pública) ajuda a reequilibrar as forças sociais em disputa e orienta a formulação de estratégias de compromisso com uma causa em comum, ao invés de mera submissão às normas de controle (Ângulo, 2007). A categoria da negociação é central no processo e para tal a elegemos como foco de análise para avaliar a consistência do modelo de regulação ora em fase de implementação.

\section{Os referenciais e as motivações primeiras}

A lógica dos modelos de avaliação em larga escala,ora em condição de hegemonia, tem gerado um conjunto de respostas adaptativas das escolas às exigências das 
políticas, que responsabilizam unilateralmente a equipe escolar pela precariedade dos desempenhos dos estudantes nos exames a que são submetidos. Esta presteza em dar respostas às pressões externas nem sempre tem repercutido nas aprendizagens dos estudantes de forma substantiva, visto que desconsidera a relevância do debate sobre os fatores que afetam esta proficiência e que são complexos e multirreferenciais. Paradoxalmente, induzem a uma adesão acrítica à concepção de qualidade que norteia a elaboração de matrizes de referências, as quais trazem implícitas visões de mundo, de homem e de educação que reclamam por contestação.

\begin{abstract}
Os instrumentos técnicos dos exames nacionais efetuam a elementarização dos fenômenos complexos das aprendizagens e da própria educação, pois precisam fazer a homogeneização tanto da diversidade do estudantado como dos conteúdos mínimos a serem cobrados e analisados o quanto possível objetivamente, fazendo abstração das dimensões emocionais, éticas, políticas, sociais que também constituem a subjetividade da vida humana. (Dias Sobrinho, 2010, p. 219)
\end{abstract}

A proposição de modelos de avaliação, que tomem a escola como unidade de referência para pronunciar-se sobre o tipo de qualidade de ensino que se compromete a produzir, é crucial para realinhar os vetores que interferem neste resultado. Freitas (2007) tem chamado isso de "mecanismo de contrarregulação" e envolve a ideia de reações propositivas a políticas de regulação regidas pelo viés mercadológico e pela responsabilização vertical. Nesta perspectiva, temos nos aproximado de experiências em desenvolvimento em redes de ensino públicas que contestam os reducionismos da avaliação externa, dispondo-se a exercitar modelos alternativos de regulação da qualidade do projeto educativo, nos quais autonomia e responsabilização dos diferentes atores se integrem numa base axiológica norteada pelos direitos da sociedade de ter uma escola pública comprometida com aprendizagens significativas e extensivas a todos os estudantes.

A experiência de avaliação institucional participativa (AIP), adotada pela rede municipal de Campinas como política de governo, tem despertado nosso interesse investigativo, especialmente porque se ancora na categoria da negociação multiatores e instâncias. Negociação é a categoria que permite a realização de acordos entre os diversos segmentos interessados na qualidade da escola pública e serve de mediação entre o que existe e o que precisa ser construído pela escola, rumo à concepção de qualidade desejada.

O termo "negociação" causa certo desconforto no campo da educação. Fruto da visão mercadológica que percorre esta área, observamos que o uso de palavras que parecem reforçar o viés mercantilista é objeto de crítica por parte de alguns. Negociar, no âmbito da política de AIP, não pode ser entendido como sinônimo de barganha realizada à custa de prejuízo imposto a terceiros, sobretudo aqueles segmentos mais fragilizados no diálogo, exatamente pelo jogo assimétrico das relações de poder que os 
envolvem. Trata-se de legitimar a ideia de que atores diferentemente situados no projeto da escola podem, pelo diálogo, estabelecer negociações em torno dos problemas a resolver e das metas a atingir, permitindo-se demandas bilaterais.

Se por longo tempo temos visto as palavras constituintes de nossos discursos inovadores serem capturadas por modelos tradicionais, servindo a fins de ocultamento de interesses ligados à manutenção das estruturas vigentes nos processos de trabalho de que participamos, acreditamos que, igualmente, podemos sequestrar alguns destes vocábulos e reconvertê-los à luz de referenciais teoricamente mais legítimos, sob o ponto de vista de sua pertinência social. Assim deve ser compreendida a categoria negociação.

Mehry (2005, p. 198) nos lembra que temos poder de engravidar as palavras, emprestando-lhes novos sentidos e significados por meio do uso que fazemos destas na concretude de nosso trabalho: "Somos fabricantes de atos produtivos carregados de intencionalidades em nossa forma individual de marcar as relações coletivas que travamos no espaço da gestão do trabalho. Isso faz do fazer um ato coletivo e implicado.

Barroso (2003) aponta que não há uma forma de regulação que se imponha simplesmente sem que ocorram microrregulacões locais, ou seja, há espaços de resistência e isso nos estimula a destacar a força da categoria da negociação como forma que pode humanizar os processos de regulação, devolvendo-lhes a dialeticidade pela incorporação das vozes dos diferentes atores sociais.

Para extrairmos melhores resultados de processos de regulação da qualidade da escola que valorizam categorias da participação e da negociação, o que pressupõe democratização na gestão da escola, temos que inicialmente compreender a cultura de avaliação historicamente construída. Há a necessidade de melhor entender o que se passa quando alguns atores sociais contestam a regulação externa sobre o trabalho da escola. Negam o controle ou determinados tipos de controle que não se realizam de forma transparente e democrática? Rejeitam a avaliação a priori ou os usos distorcidos daquilo que se denomina de forma conveniente como avaliação?

A escola pública não pode esquivar-se do compromisso com a aprendizagem das crianças e isso inclui todas as crianças. Nada pode justificar o abandono de algumas à condição de não-aprendizagem. Menos ainda, podemos aceitar sem perplexidade o discurso da meritocracia para explicar o fracasso da escola junto a estas crianças.

A regulação sistêmica é legitima e deve ser feita pelo poder público em nome do direito das crianças às aprendizagens. Como aceitar que os estudantes sejam expostos a trabalho pedagógico que não promova aprendizagens até que os profissionais aceitem ser avaliados? 
O que dizer de escolas de desempenho baixo que não fazem nada ou que rejeitam de forma explícita inovações potencialmente efetivas? Não se pode permitir que continuem em sua inação com base na visão de que as decisões comunitárias são a única maneira de agir. (Fullan, 2009, p. 83)

Exatamente pela crença que temos na avaliação, como prática social e estratégia de ação e de compromisso com concepções ampliadas de qualidade, contestamos a ideia de que a deflagração de processo de avaliação de qualquer natureza seja suficiente para que as melhorias nas e das aprendizagens ocorram.

Admitindo que a qualidade da educação, sobretudo na escola pública, é processo marcado por disputas entre cosmovisões que concorrem para imprimir determinados conhecimentos e valores que subsidiam a formação do Homem (e não apenas do trabalhador), defendemos que esta qualidade praticada pela escola seja monitorada ativamente e receba retroalimentações plurais, multifacetadas e detentoras de pertinência social. $O$ tipo de qualidade escolar que ajudamos a construir nos desafia a problematizar os formatos avaliativos que nos são apresentados e a rever a forma como podemos interferir no processo, por meio das microrregulações que fizermos.

Não há como combater políticas de avaliação que se contentam com a melhoria das estatísticas escolares por meio da responsabilização unilateral da equipe escolar, sem construir legitimidade política junto aos atores implicados na orquestração de ações voltadas à qualificação da escola pública. Estes, sentindo-se força atuante na vida da escola, podem aprender a enxergar com mais nitidez as inegáveis contribuições que a avaliação oferece.

Por mais paradoxal que possa parecer, atores antes reticentes frente às regulações externas podem propositivamente desenvolver e/ou participar de processos alternativos de avaliação, se recuperarem sua titularidade nos mesmos.

Uma regulação mediada pela negociação corrobora os resultados de Bryk e Schneider (2002), que destacam a importância da confiança nos atores da escola, lembrando que a microdinâmica da confiança envolve um mix complexo de motivações individuais. A decisão de um individuo de se engajar ou não em ações com outros indivíduos - o que incorpora inclusive a aceitação de algum risco - é fortemente afetada pela confiança existente nas relações que estes mantêm entre si e que são regularmente revisitadas.

Modelos de avaliação institucional participativa (AIP), ao elegerem a negociação como categoria de ação mobilizadora dos atores envolvidos no processo, positivamente os afetam ao despertar-lhes o sentimento de pertencimento a um coletivo, do qual fazem parte e no qual podem fazer diferença. 
A implicação como atores sociais estabelece como trilha de trabalho educacional uma atuação centrada nos direitos inalienáveis dos estudantes ao aprendizado. Gera comprometimento de todos com a alteração das estatísticas escolares que informam, de modo privilegiado, o quanto as práticas pedagógicas desenvolvidas têm alcançado as metas a que o coletivo se dispôs nas condições objetivas em que atuam. Deste modo, recriam-se formas de diálogo que remetem a um tipo de controle social legítimo e que se confrontam com a responsabilização típica dos modelos neoliberais de avaliação.

Busca-se assim reconfigurar o lugar dos trabalhadores da educação, que saem da condição de "recursos humanos" para serem introduzidos ou recuperarem seu estatuto de sujeitos protagônicos. Estes não podem ser vistos ou tratados como atividades-meio de um setor, meros recursos humanos para serem geridos à semelhança de recursos materiais, financeiros, tecnológicos ou logísticos (Ceccin, 2005).

\section{A experiência de avaliação da Secretaria Municipal de Educação de Campinas tomada como pretexto}

A decisão política de implementar a avaliação institucional como eixo estruturante do projeto de avaliação das 44 escolas de ensino fundamental, da Secretaria Municipal de Educação (SME) de Campinas, ocorreu em 2008, com a fixação de prazos para a constituição de Comissões Próprias de Avaliação (CPAs) e a subsequente formulação do plano de avaliação de cada escola devidamente articulado com o projeto pedagógico anualmente entregue à SME como um dos mecanismos de regulação adotados. Esta decisão pode ser considerada como tributária do movimento de reflexão sobre avaliação da qualidade do ensino, iniciado em 2002 junto às equipes gestoras da rede municipal, que culminou com a formulação de uma "Carta de Princípios" que rege o compromisso da universidade pública local de assessorar a SME no processo de implementação desta política de avaliação, enquanto os princípios ético-epistemológicos consensuados forem seguidos.

O Projeto de Avaliação Institucional Participativo (AIP) se vale da forma de organização da SME já existente, estruturando-se em um departamento pedagógico (Depe) que atua de forma descentralizada, por meio da ação de cinco Núcleos de Ação Educativa Descentralizada (Naed) distribuídos por região. Estes núcleos responsabilizam-se pelo apoio pedagógico às escolas da região e pela supervisão do trabalho executado em conformidade com a legislação vigente (Sordi \& Souza, 2009).

Podem ser compreendidos como o nível meso de abordagem da avaliação, cabendo-lhes regular as escolas e sustentar a política de educação e avaliação propostas. No nível das escolas, uma equipe gestora, composta por diretor, vice e 
orientador pedagógico (OP), complementa-se na gestão do projeto pedagógico (PP) e esta, conforme consta, deve ser democrática.

O Projeto de AIP proposto para a rede foca-se inicialmente na estratégia de relocalização da avaliação no nível de cada escola (espaço micro) e designa o OP como o articulador deste trabalho junto à CPA local, constituída por representantes de todos os concernidos com a qualidade da escola pública, convocados ao trabalho coletivo. Observa-se que a forma de organização da rede se mantém. Porém, busca-se alterar a natureza do trabalho desenvolvido, fortalecendo as relações entre os atores.

O OP, no desenho avaliativo concebido, exerce função articuladora dos atores da escola para que estes intensifiquem e flexibilizem suas formas de inserção no PP da escola, estimulando o pertencimento e a colaboração ativa, componentes fundamentais para potencializar o trabalho do coletivo na direção de uma escola comprometida com as aprendizagens dos estudantes.

A equipe gestora é compreendida como força mediadora e garantidora do projeto, constituindo-se igualmente como objeto da avaliação. Observa-se que por meio da AIP busca-se reorganizar os coletivos da escola, de modo que possam operar em colaboração, rompendo as formas de organização de processos de trabalho nas escolas que, apesar de adjetivados como democráticos, estruturam-se de forma piramidal, não deixando ver nada além da hierarquização numa racionalidade que não se afasta da lógica administrativa e gerencial hegemônica.

A noção de "coletivo organizado" acresce, ao conjunto de pessoas interligadas por uma tarefa com finalidade produtiva, uma convergência, uma intencionalidade forte, uma composição em roda ou mandala, conforme descreve Ceccin (2005, p. 166):

(...) a característica mais marcante de um diagrama em mandala é que seu traçado é feito em torno de um centro, geralmente obedecendo a eixos de simetria e pontos cardeais. O circulo exterior não é necessariamente uma esfera e sua expressão não é mesmo a das formas geométricas, mas a de movimento, passando sempre a ideia de irradiar-se de um centro ou mover-se em direção a ele. Como nas rodas de ciranda, o diagrama de uma mandala é uma coreografia de dobras, isto é, uma rede em que múltiplos pontos, diversos em si, convergem ao centro e compõem um sistema único, contido por um diagrama: o da mandala. A hierarquização seria então o desenho dos eixos de comunicação, das linhas de cuidado e dos pontos de planificação do matriciamento do trabalho, das equipes, das referências em rede. A regionalização seria o desenho de zonas em torno dos pontos de contato e cruzamento onde se constroem pactos entre gestores locais, linhas de cuidado cooperativas e laços solidários com as redes sociais.

Um coletivo organizado não configura necessariamente uma unidade; ele não é um organismo, mas um dispositivo de ação. O que dá organização ao dispositivo coletivo organizado não é a "identidade entre seus membros, mas seu objetivo de produção". Em síntese: 
(...) nós de articulações locorregionais e interinstitucionais, visibilidade e enunciação de múltiplos agentes com voz e vez, efetiva descentralização com múltiplos pontos de contato e participação ampliada, tendo como centro ou orientação ao centro, os usuários. (Idem, ibid., p. 170)

No espírito de um coletivo-dispositivo não cabe o organograma, somente diagramas, emaranhado de linhas que se organizam e desorganizam para assegurar sua produtividade. Evidentemente, aqui falamos de uma produtividade com qualidade social.

O desafio é o de transmutar a racionalidade administrativa e gerencial hegemônica para uma visão de trabalho vivo, que se faz em ato, onde operam processos e relações e não a hegemonia da técnica, dos procedimentos, dos protocolos e das rotinas que antecedem o contato real com cada usuário, com cada colega de equipe, com cada serviço singularmente inserido em uma rede. Mehry (2005) cunhou a expressão trabalho vivo em ato para destacar as forças vivas cunhadas pelas tecnologias leves (das relações) no trabalho, um trabalho fundado na interação, na cogestão administrativa que envolve implicação e compromisso com a produção de si e do mundo.

Disso decorre que, ao se falar em negociação como categoria decisiva no processo de AIP, condições anteriores de democracia na gestão do PP da escola precisam estar asseguradas, ainda que não necessariamente ocorram isentas de contradição. Um diagrama em forma de mandala parece-nos interessante, no sentido de produzir novas configurações no trabalho escolar, sem as quais o processo de avaliação institucional participativa não comporta a arte de negociação.

Uma regulação mediada por um pacto de qualidade negociado entre diferentes atores não é atividade que ocorre sem conflitos, dadas as visões marcadas pelos lugares sociais dos sujeitos implicados. Assim, a mudança pretendida pode até ser tecnicamente simples, porém é socialmente complexa. A convocação dos atores internos e externos à escola, situados no centro ou na periferia da rede, implica trabalho de alta densidade ético-epistemológica. Trata-se de tornar claro o tipo de qualidade que se deseja construir, a partir do reconhecimento do padrão de qualidade existente na escola/rede e para o qual esse coletivo organizado se dispõe a trabalhar, rumo ao aprimoramento do projeto pedagógico.

Aprendizagens de participação/negociação não podem se converter em estratégias de mobilização dos atores da escola contra o poder central. Nem pode o poder central abster-se de sua responsabilidade e ficar passivamente aguardando os resultados das escolas. Para que a negociação multiatores e multi-instâncias aconteça, é necessário que sejam planejados espaços de encontro que os coloquem em condição de diálogo. 
A estratégia da CPA foi formulada para estimular a aproximação dos atores sociais implicados no projeto da escola. Parece ser potente para que estes exercitem sua capacidade dialógica e iniciem, no âmbito interno, negociações com seus pares, fortalecendo-se para demandar responsavelmente, num segundo momento, as condições necessárias para a produção de qualidade de ensino sob as quais não têm governabilidade, convocando o poder público a assumir seu papel e a se envolver visceralmente com o pacto de qualidade negociado.

Em processos de regulação da qualidade da escola, os representantes do poder público são também considerados protagonistas e, como tal, possuem expectativas referenciadas no direito das crianças às aprendizagens. O lócus que ocupam confere-lhes autoridade e legitimidade para demandar da escola compromisso com os direitos dos estudantes. Paralelamente, possuem e devem demonstrar responsabilidade com as condições objetivas em que operam as escolas, prestando contas publicamente do que estão fazendo ou das razões que obstaculizam o fazer aquilo que precisa ser feito, atendendo às demandas responsavelmente trazidas pelas escolas.

Considerando que a categoria negociação, na perspectiva do projeto de avaliação da SME de Campinas, constitui campo de aprendizagem para todos os atores envolvidos no processo e que a capacidade de desenvolver negociações regidas pelos interesses dos estudantes é favorecida pelos princípios da continuidade, historicidade da experiência, entendemos ser importante monitorar longitudinalmente como têm ocorrido as reuniões de negociação entre as CPAs das escolas e os representantes do poder público municipal de Campinas (SME), tópico que abordaremos a seguir.

\section{Comissão Própria de Avaliação (CPA) como lócus primeiro de nego- ciação}

A concepção de avaliação que orienta o projeto de AIP adotado pela SME está assentada nos princípios da globalidade, da continuidade, da historicidade dos processos, da legitimidade técnica e política. Confronta-se com a lógica de avaliação predominante no cenário político atual das políticas de regulação, ao rechaçar o viés classificatório e ranqueadore afastar-se do artifício da punição e/ou da premiação dos atores como motivação para que a escola progrida; reconhece a especificidade do fenômeno educacional, o que exige especial atenção aos processos, rompendo com o viés de apenas avaliar resultados.

Enquanto um objeto qualquer se deixa avaliar depois de pronto, o produto da educação, por ser sujeito, dotado de vontade, e em virtude das qualidades que o caracterizam, e que precisam, portanto, ser avaliadas, não pode ser avaliado pelos sistemas usuais de 
aferição de um objeto qualquer, nem pelas provas e pelos testes utilizados para aferir conhecimentos. (Paro, 2011, p. 707)

A indissociabilidade entre processo/produto; a articulação do olhar interno e externo; o diálogo entre as várias dimensões que compõem a totalidade do fenômeno a ser avaliado e a agregação de aspectos qualitativos a processos anteriormente centrados em números são algumas das bases orientadoras do modelo, cuja intenção é a de afetar o paradigma comumente presente nos processos de avaliação da qualidade educacional e promover uma cultura avaliativa mais consequente, sob o ponto de vista da relevância social.

Embasada na versão original do Sistema Nacional de Avaliação da Educação Superior (Sinaes) e por meio do enfrentamento das contradições que perpassaram o processo de implementação desta política na educação superior, a arquitetura do projeto avaliativo da SME convoca a participação plural dos atores envolvidos no processo de qualificação das escolas de ensino fundamental. Essa participação é sustentada por meio de ações gestadas no nível de CPAs instaladas em cada unidade escolar.

As CPAs foram concebidas como estratégia agregadora das forças sociais existentes e atuantes no cenário das escolas, para ações de diagnóstico situacional e eleição de prioridades, com vistas à proposição de encaminhamentos sintonizados com a imagem desejadade futuro institucional. Embora não tenham poder decisório, restauram na cena avaliativa o princípio da legitimidade política para identificar potências e fragilidades do projeto pedagógico que interferem nas aprendizagens dos estudantes, sistematizar ações, demandar e encaminhar às instâncias oficiais as necessidades e condições objetivas para que a qualidade se configure como possibilidade e não apenas como discurso.

O foco do trabalho das CPAs ambiciona primeiramente instrumentalizar o debate interno sobre qualidade, subsidiando o processo decisório local e colocando-o a serviço do PP. Decorrente da organização dos atores em torno do pacto de qualidade que negociam e com o qual se comprometem, espera-se responder também às exigências da avaliação externa e ao processo de regulação estatal, porém com outra lógica de ação que toma os índices como um dos balizamentos para o processo decisório e não o indicador. Sob a coordenação do OP, os debates da CPA subsidiam a identificação plural dos problemas a partir das múltiplas visões e expectativas, o consenso sobre as prioridades definidas para o ano letivo e renovadas periodicamente e a explicitação de metas de cunho quali-quantitativo que ensejam o monitoramento da proposta (princípio da transparência e do controle social).

No cenário mais protegido da escola, atores internos e externos vão aprendendo a participar autenticamente do projeto pedagógico. Favorecidos por práticas 
de gestão democrática, estes atores vão desenvolvendo a capacidade de vocalizar suas visões de qualidade, exercitando o princípio da negociação com os pares. Esta negociação envolve compromissos individuais e coletivos com a obra comum que buscam edificar, o que os autoriza a demandar responsavelmente pelas condições que auxiliam objetivamente a concretizá-las.

Tal pacto ganha envergadura política, pois resulta de aliança multiatores construída no chão das escolas e que fortalece os futuros diálogos com o poder central, quando a natureza dos problemas a resolver ultrapassa a zona de governabilidade da escola.

Ressaltamos que as CPAs podem constituir espaço favorecedor do encontro dos atores sociais envolvidos na qualificação do projeto da escola, estimulando sua organização em torno de causa comum. Disso deriva a tensão saudável entre interesses privados e coletivos e a CPA pode funcionar à semelhança da ágora citada por Bauman (2000, p. 11):

(...) esse espaço nem privado nem público, porém mais precisamente público e privado ao mesmo tempo. Espaço onde os problemas particulares se encontram de modo significativo - isto é, não apenas para extrair prazeres narcisísticos ou buscar alguma terapia através da exibição pública, mas para procurar coletivamente alavancas controladas e poderosas o bastante para tirar os indivíduos da miséria sofrida em particular; espaço em que as ideias podem nascer e tomar forma como "bem público", "sociedade justa" ou "valores partilhados".

A incorporação da categoria da negociação nos processos de regulação ajuda a reorientar os usos da avaliação, colocando-os a serviço das aprendizagens. Estas envolvem as crianças inicialmente, mas igualmente fomentam, nos diferentes concernidos do processo, aprendizagens que envolvem os valores da participação cidadã.

A importância da negociação no processo de regulação do poder público sobre a qualidade das escolas da rede parece-nos interessante ainda, pois pode alterar o ânimo dos atores, devolvendo-lhes a confiança no potencial formativo da avaliação. Posturas dialógicas são inerentes a processos de avaliação, posto que estes constituem atos de comunicação com o outro. Comunicando-se, os sujeitos entram em acordo sobre os objetivos e as metas que perseguem e para os quais se dispõem a trabalhar de modo concreto.

A tendência a "forjar" resultados para melhorar os índices das escolas tem sido denunciada como decisão equivocada, mas comumente presente em algumas redes de ensino, e pode ser entendida como subproduto das políticas regulatórias hegemônicas, que responsabilizam unilateralmente as escolas pelo fracasso dos estudantes nos exames externos, impondo-lhes punições visíveis ou subliminares (Paro, 2011; Fernandes, 2009; Madaus, Russell \& Higgins, 2009). 
Quando o coletivo da escola assume seu protagonismo no processo de avaliação, este artifício deixa de fazer sentido, posto que a manipulação dos dados para melhorar o lugar da escola no ranqueamento externo não resolve a questão da qualidade da escola pública no âmbito interno. Esta qualidade será diretamente afetada pela capacidade deste coletivo se organizar e aprender a negociar condições para o cumprimento de metas, em cuja definição possui titularidade. Evidentemente, este coletivo organizado, ao decidir sobre o destino do projeto pedagógico da escola, compromete-se desde o inicio do processo até a avaliação da qualidade dos produtos.

O pressuposto é que não há linha demarcatória entre quem demanda e quem é demandado, quem avalia e quem é avaliado. Todos se responsabilizam e se comprometem na governança da escola e da rede municipal.

Jessop (citado por Simões, 2007, p. 40) define governança como:

A arte complexa de conduzir múltiplas agências, instituições e sistemas, que são simultaneamente autônomos uns dos outros e estruturalmente agregados através de diversas formas de interdependência e reforça que esta governança exige que "os parceiros sociais se comprometam com uma auto-regulação da conduta, em nome de um projecto social", funcionando o Estado como um parceiro, entre outros, legitimando-se na sua capacidade de "persuasão moral" e de "mediação da inteligência colectiva".

Os atores aprendem a realizar demandas, ora convocando a si mesmos à ação, ora convocando o outro no âmbito de sua responsabilidade, ora convocando o próprio poder público a cumprir com seu papel de garantir apoio logístico para que o trabalho docente e da escola possa se efetivar satisfatoriamente. Trata-se de algo que podemos chamar de processo de responsabilização compartilhada, em oposição ao modelo de responsabilização vertical.

Assim, de meros demandantes por resultados das escolas, desresponsabilizando-se da garantia de condições objetivas mínimas para que estas operem, ou desconsiderando o conjunto de fatores que concorre para o fracasso escolar, os representantes do poder público ganham, pela via do pacto de qualidade negociada com as escolas, outro estatuto que lhes confere legitimidade para demandar, exatamente porque aceitam ser demandados e, com transparência, aceitam também discutir os limites e contradições da própria política, na medida em que esta necessita garantir condições básicas para que a escola exerça seu trabalho, devidamente sintonizado com o processo de qualificação ambicionado.

O poder central amplia seu direito/dever de demandar das escolas o cumprimento de metas, sobretudo aquelas ligadas às aprendizagens dos estudantes, expressas também pelos resultados obtidos nos exames nacionais, quando não se omite no processo de luta por uma escola pública de qualidade. E isso implica a 
manutenção de condições objetivas que lhe compete garantir para que as escolas desenvolvam seu trabalho.

Esclarecida a centralidade da categoria da negociação no modelo avaliativo implementado pela SME, optamos por problematizar os encontros de negociação entre CPAs e gestores centrais da Secretaria, descrevendo as lógicas de ação dos dois segmentos. O pressuposto é de que a negociação multiatores iniciada nas escolas auxilia a fortalecer o protagonismo local e favorece o diálogo com atores situados em outras instâncias decisórias que, comumente nos processos hegemônicos de regulação da qualidade, tendem a posturas de controle vertical.

O modelo regulatório em fase de implementação pela SME orienta-se pelo pilar da emancipação e, por conseguinte, pretende-se que seja dialógico, participativo, favorecendo experiências de negociação de mão dupla. Pretendemos identificar as concepções de qualidade educacional e de avaliação presentes, sua aderência ao projeto de AIP e as distinções entre o primeiro encontro e o segundo que possam denotar avanços ou claudicações do processo de negociação multiatores e multi-instâncias.

\section{Regulação da qualidade da escola pública mediada pela negociação entre gestores e CPAs das escolas}

A negociação entre os atores implicados no processo de qualificação das escolas de ensino fundamental de Campinas pareceu-nos alternativa potente para sustentar regulações orientadas pelo pilar da emancipação. Considerando que este é um processo ainda em construção, e que tem contra si não apenas a cultura de avaliação hegemônica, como também certa falta de confiança dos atores locais da escola nos gestores situados no nível central do sistema educacional e nas políticas públicas vigentes, buscamos apresentar alguns subsídios para examinar de perto a consistência do modelo.

Elegemos como objeto de estudo as reuniões de negociação agendadas pela SME para cumprir o disposto na política de AIP. Consideramos estes encontros entre o poder público central e as escolas como o ápice da negociação, exatamente pela originalidade da proposta que envolve ambos os segmentos em processo de responsabilização participativa.

Foram realizados dois eventos desta natureza desde o início da implementação da política. O diálogo direto entre o secretário de Educação e os representantes das CPAs ocorreu por meio da organização das escolas em grupos de até seis. Estes eventos foram propostos como desfecho dos processos de negociação realizados anteriormente no nível das escolas por meio de CPAs. Tiveram início em 2010, posto que antes as formas de diálogo topo/base encetadas pela SME voltaram-se 
mais para a sensibilização das escolas e suas CPAs, enfocando as percepções dos segmentos sobre as fragilidades e potencialidades do modelo avaliativo em desenvolvimento.

Construídas as condições políticas necessárias, avançou-se para a etapa de negociação das escolas com o poder central. A conversa entre as partes foi orientada pelo Plano de Avaliação encaminhado pelas escolas, destacando-se as metas pedagógicas por elas traçadas e que, a seu ver, mostravam-se dependentes do apoio central para sua consecução.

Os dois encontros, similares em seus objetivos, tiveram dinâmicas distintas em função tanto de mudanças inerentes ao próprio processo de implementação da política de AIP, como de outras ocorridas na estrutura organizacional da Secretaria de Educação que implicaram alteração da equipe gestora central. A alteração do cenário político local gerou dúvidas sobre a continuidade da política de AIP concebida como reação propositiva a modelos de regulação da qualidade da escola, centrados nos resultados dos estudantes nos testes de desempenho padronizados.

O quadro a seguir sistematiza alguns aspectos dos encontros de negociação que consideramos importantes para entender o contexto dos mesmos. Foi construído a partir da observação in loco das reuniões realizadas, com registro das impressões feitas por dupla de pesquisadores e posterior cruzamento das perspectivas de análise.

\section{Aprendendo a negociar: apropriações processuais e significados possíveis}

A concepção do projeto de AIP e a decisão de implementação como uma política da SME contrastada com as várias mudanças de secretários de Educação que ocorreram no município fazem-nos realçar o peso que os discursos e posturas destes atores tiveram nos encontros de negociação. Nos dois encontros, observou-se alguma ansiedade nos membros das CPAs, explicada pela inexperiência em participar de um processo em que demandados e demandantes se encontram, em nome de um pacto de qualidade em favor da escola pública, e depois pela descontinuidade das pessoas que representam o poder central no processo de negociação.

O estabelecimento de prioridades educacionais em escolas, cujos cenários se caracterizam pelo alto grau de vulnerabilidade social da população do entorno e pela heterogeneidade das condições objetivas de trabalho, torna complexo o processo decisório central que precisa embasar-se em dados confiáveis e objetivos para escapar do subjetivismo e do clientelismo. Isso afeta os representantes do poder público, que deixam entrever algum desconforto com a situação de diálogo com cada coletivo escolar, dada a pertinência das demandas endereçadas ao poder público. 
A cultura de atender a pedidos individuais dos diretores, desprovida da visão de conjunto da rede de escolas e desgarrada do processo de avaliação da qualidade, se altera quando se negocia com vários atores sociais simultaneamente. Isso exige transparência valorativa e coerência na exposição dos motivos e das regras do jogo para dizer sim e dizer não a cada unidade escolar. A tensão presente neste novo processo relacional pode ser evidenciada por meio de alguns excertos das falas oficiais que selecionamos como relevantes para expressar o entendimento da política de AIP e o sentido da categoria negociação. Denominaremos como S1 e S2, respectivamente, os responsáveis pela condução dos encontros de 2010 e 2011. Cabe destacar que ambos os secretários não eram pedagogos e tinham sido reitores de universidades locais. Possuíam repertório no campo da gestão educacional, embora restrito à educação superior.

\section{Quadro 1}

Aspectos dos encontros de negociação entre CPAs e representantes do poder público municipal (Campinas, 2012)

\begin{tabular}{|c|c|c|}
\hline & Negociação 2010 & Negociação 2011 \\
\hline Ênfase do encontro & $\begin{array}{l}\text { Instrumentalização técnico- } \\
\text { política da comunidade para } \\
\text { entendimento do processo da } \\
\text { negociação }\end{array}$ & $\begin{array}{l}\text { Efetivação da negociação entre } \\
\text { as partes orientada pelo Plano de } \\
\text { Avaliação revisitado }\end{array}$ \\
\hline Participantes & $\begin{array}{l}\text { - Secretário da Educação } \\
\text { - Coordenadora da AIP } \\
\text { - Representante do Depe } \\
\text { - CPAs das escolas }\end{array}$ & $\begin{array}{l}\text { - Secretário da Educação } \\
\text { - Coordenadora da AIP } \\
\text { - Representante do Depe } \\
\text { - CPAs das escolas } \\
\text { - Representantes de órgãos de } \\
\text { apoio da SME } \\
\text { - Representantes Naed }\end{array}$ \\
\hline $\begin{array}{l}\text { Número de escolas } \\
\text { participantes (grupos } \\
\text { de } 5 \text { ou } 6 \text { ) }\end{array}$ & 32 & 36 \\
\hline $\begin{array}{l}\text { Dinâmica dos } \\
\text { trabalhos }\end{array}$ & $\begin{array}{l}\text { Metodologia tradicional (fala } \\
\text { oficial da mesa; demandas das } \\
\text { CPAs; respostas por blocos) }\end{array}$ & $\begin{array}{l}\text { Foco nas demandas pedagógicas } \\
\text { das CPAs, estruturadas a partir } \\
\text { de um roteiro comum, seguidas } \\
\text { de respostas do poder público } \\
\text { dirigidas a cada escola }\end{array}$ \\
\hline Clima do encontro & $\begin{array}{l}\text { Descontraído, tomada de } \\
\text { palavra livre e posicionamento } \\
\text { dos vários segmentos das } \\
\text { CPAs }\end{array}$ & $\begin{array}{l}\text { Fala estruturada e mais formal } \\
\text { dos representantes da escola; } \\
\text { segmentos da CPA mais inibidos }\end{array}$ \\
\hline
\end{tabular}


Implicações ético-epistemológicas da negociação nos processos de avaliação institucional...

\begin{tabular}{|l|l|l|}
\hline Postura CPA/escola & $\begin{array}{l}\text { Submissa à metodologia linear } \\
\text { do processo }\end{array}$ & Proativa, argumentativa \\
\hline $\begin{array}{l}\text { Concepção de } \\
\text { negociação das CPAs } \\
\text { e equipes gestoras }\end{array}$ & $\begin{array}{l}\text { Predominância de expectativas } \\
\text { de respostas concretas, tipo } \\
\text { lógica do balcão }\end{array}$ & $\begin{array}{l}\text { Lógica de demanda situada } \\
\text { historicamente e com sustentação } \\
\text { em dados e na teoria }\end{array}$ \\
\hline $\begin{array}{l}\text { Condução do } \\
\text { processo de } \\
\text { negociação pelo } \\
\text { poder central }\end{array}$ & $\begin{array}{l}\text { Formativa, contextual, baixa } \\
\text { resolutividade dos problemas e } \\
\text { negociação tímida }\end{array}$ & $\begin{array}{l}\text { Pragmática, busca de } \\
\text { resolutividade e fixação de prazos } \\
\text { e definição de responsáveis }\end{array}$ \\
\hline $\begin{array}{l}\text { Alusão aos índices } \\
\text { externos }\end{array}$ & $\begin{array}{l}\text { Presença tênue com maior } \\
\text { destaque aos indicadores } \\
\text { internos }\end{array}$ & Alusão presente e circunstanciada \\
\hline $\begin{array}{l}\text { Predominância das } \\
\text { demandas das escolas }\end{array}$ & $\begin{array}{l}\text { Melhoria da infraestrutura, } \\
\text { recomposição do quadro } \\
\text { funcional e docente; baixa } \\
\text { alusão aos problemas } \\
\text { pedagógicos }\end{array}$ & $\begin{array}{l}\text { Recomposição do quadro } \\
\text { docente; alusão maior aos } \\
\text { problemas pedagógicos }\end{array}$ \\
\hline Clima pós-reunião & $\begin{array}{l}\text { Satisfação dos segmentos das } \\
\text { CPAS; } \\
\text { Desapontamento das equipes } \\
\text { gestoras com a recorrência dos } \\
\text { problemas e das explicações } \\
\text { consideradas como evasivas }\end{array}$ & $\begin{array}{l}\text { Maior satisfação com os retornos } \\
\text { dados a cada escola em particular }\end{array}$ \\
\hline
\end{tabular}

A fala de S1, que marca o primeiro encontro entre o poder público e as CPAs, é de cunho formativo, mostrando-se cuidadoso para explicar o sentido que a negociação tem para a SME e revelando amplo domínio do projeto de AIP, embora não tenha participado do processo de sua concepção:

“Convém recordar que este processo é novo para todos da rede e que envolve uma aprendizagem gradativa. Vamos aprender a negociar fazendo a negociação". (S1)

“Não existe certo ou errado no processo de avaliação. Temos que apontar as ideias, discutir visões/sugestões. Explorar e enriquecer o processo, minimizar chances de caminhos deficientes. Quando algumas ações surtem efeito, os desafios vão se ampliando, nos tornaremos mais exigentes no que desejamos. É processo". (S1)

Em relação ao processo de negociação, observam-se diferenças na forma de lidar com a categoria na perspectiva do projeto de AIP proposto pela SME. S2 parece incomodado com o uso do termo, para o qual atribui valor negativo, e se reporta à necessidade de trocar o nome. S1 demonstra maior clareza do sentido da categoria negociação no projeto e revela apropriação das bases teóricas que lhe 
dão sustentação. Esforça-se para garantir o afinamento conceitual entre os atores e para destacar a forma como a SME vê as CPAs das diferentes escolas:

\begin{abstract}
"Sabemos que são realidades distintas e cada CPA deve indicar as metas que quer atingir. O que não pode é ficar indiferente. Precisamos saber o que as escolas precisam para melhorar estes indicadores de qualidade. Tão logo a Secretaria atenda as demandas ou parte delas, a Secretaria tem o direito de esperar que os índices melhorem. Na mesma proporção do atendimento que fez. Isso é negociação. Firmar um compromisso, fechar um acordo entre as partes". (S1)

“Qualquer lado que não cumprir o combinado contribui negativamente para o resultado. Se a SME dá conta da sua responsabilidade e a escola abandona o compromisso, o indicador não melhora e vice-versa". (S1)

“Não gosto do nome que deram. Negociação lembra dois lados e um que precisa convencer o outro, aquele que tem poder para resolver o problema. Não vejo deste modo, entendo que a filosofia do encontro é chegar ao melhor resultado possível. Eu pertenço à escola e a escola me pertence. Não somos inimigos". (S2)

"A área central formula políticas para dar apoio aos que estão na ponta para garantir o sonho das crianças. O nome pouco importa, mas acho que devemos mudar. Quem sabe algo tipo 'Luta pela qualidade'”. (S2)

“Os problemas devem ser colocados com firmeza e com confiança. Penso ser semelhante à relação pai/mãe/filhos. Só se reclama quando se confia. Não se apresenta o problema se não achar que pode ser resolvido. Mas o que não puder ser feito tem que ser explicado". (S2)
\end{abstract}

Outro destaque que julgamos interessante discutir refere-se à expectativa de resolução dos problemas por parte das escolas e a forma como o poder público se apresenta diante destas, lembrando a historicidade, a intersetorialidade e enfatizando o Plano de Avaliação como mediador do diálogo topo/base com necessidade de registro longitudinal dos problemas, das demandas e dos indicadores de monitoramento dos avanços. O processo de negociação requer confiança entre os envolvidos e comprometimento com a aprendizagem das crianças. A inclusão dos problemas no Plano de Avaliação é lembrada como estratégica, cabendo à CPA negociar as prioridades sob a ótica da escola e admitir que estas prioridades serão negociadas também em âmbito maior (o da rede de ensino). Isso implicará a aceitação de que alguns problemas, apesar de legítimos, terão sua resolução ao longo de um tempo, o qual deverá ser socializado para permitir controle social sobre os caminhos e descaminhos da demanda. S1 apresenta-se mais situado e comprometido com a formatividade do encontro. S2 dialoga com facilidade com a comunidade das escolas e o tom de suas intervenções ao final parece ser mais resolutivo.

\footnotetext{
“Nem todas as demandas poderão ser atendidas. Algumas são difíceis no curto prazo, mas precisam ser criadas as condições para que possam vir a ser atendidas. Por isso é necessário incluí-las no Plano e deixá-las registradas para que se continue a luta para que elas possam ser resolvidas. Para que se possa cobrar responsabilidade". (S1)
}

Educ. Soc., Campinas, v. 33, n. 119, p. 485-510, abr.-jun. 2012 


\begin{abstract}
"Vale lembrar que o objetivo principal é garantir a aprendizagem das crianças e assim a hierarquização das prioridades deverá levar em conta o quanto esta afeta o trabalho pedagógico. Outras limitações serão parciais e assim poderão esperar um pouco mais. Se a CPA aprender a pensar sobre o quanto a demanda que inclui no plano afeta o pedagógico, ela se situará melhor na negociação com a Secretaria". (S1)

"Penso ser necessário perseguir as soluções mesmo quando as demandas não conseguem ser atendidas. Diagnósticos geram debates e firmam-se metas ao longo de um tempo. Precisa estudar o assunto, circunstâncias. Por exemplo, quando reduzo a evasão, mesmo que eu não a elimine da primeira vez, isso é melhoria. Pode não ter zerado, mas é avanço. Vai ser paulatino até atingir meta da idealidade". (S1)

“A construção da qualidade é um processo que tem que nos desafiar para que a gente não esmoreça. 'Fiz mais hoje do que fiz ontem'. As unidades escolares trouxeram a realidade da escola com muita riqueza. E vejo que a SME precisa de um 'choque de gestão'. Reunião de negociação vai ajudar a formular diretrizes. É necessário descentralizar, decidir, fazer algumas coisas para o pedagógico deslanchar". (S2)

“Tem todo um quadro político complicado. Ninguém sabe o que vai acontecer, quem vai ficar. Tenho falado com todos 'os prefeitos' possíveis. A prioridade é abrir concurso e garantir professor na sala de aula". (S2)
\end{abstract}

O encontro de negociação da SME com as CPAs das escolas, em suas duas versões, mantém o tom do debate sobre a qualidade da escola de modo coerente com a concepção de avaliação do projeto de AIP. Os índices externos não são descartados, mas não ocupam a centralidade do diálogo. Merece destaque este dado se considerarmos a alta rotatividade dos secretários e os diferentes partidos políticos que estes representam, o que poderia ocasionar mudanças de concepção de qualidade e maior alinhamento da política de avaliação local com a lógica neoliberal que tem dominado a cena das reformas educacionais. A não mudança da lógica da avaliação nesta rede, apesar de toda a instabilidade ocorrida, nos faz pensar que os desgastes políticos podem ter sido contabilizados e desaconselhada a alteração de rota. Outra hipótese a ser examinada refere-se ao nível de enraizamento dos princípios do projeto de AIP na comunidade das escolas, o que poderia gerar resistência a tentativas de imposição de modelo de avaliação meritocrático.

Nesta direção, observa-se nítido avanço das CPAs das escolas do primeiro para o segundo momento de negociação, confirmando a importância da continuidade do processo para que a aprendizagem da participação e da negociação possa amadurecer. Parece claro que as escolas estão mais desenvoltas em 2011, favorecidas pelo roteiro que receberam da SME. Por outro lado, as diferenças identificadas na forma de condução dos encontros pelos secretários não podem ser creditadas à continuidade da política de AIP, mas às formas peculiares de condução que cada ator defende. Assim, vejamos:

"Muito embora não tenhamos criado estes indicadores que foram definidos pelo governo federal, não podemos deixar de atendê-los. Mas poderemos criar nossos próprios 
indicadores de qualidade que se agreguem a estes existentes. Vivemos momento decisivo da avaliação, tempo de transição entre o que é conceitual para gerar reflexão e ações concretas. Importante utilizar o processo para que as ações sejam práticas de aprendizagem, aprendizagem é a palavra da avaliação. É necessário transitar de uma situação para outra melhor. Esta sistemática se pereniza. É um processo contínuo". (S1)

“Lembro a inadequação de comparar o Ideb das escolas. Temos que ver caso a caso, pois o que importa é não se perder a concepção de avaliação do nosso projeto, mesmo quando se reforça a necessidade de as escolas zerarem a taxa de analfabetismo das crianças e diminuírem os números da evasão e reprovação". (S1)

“Nossa prioridade será garantir o professor na sala de aula para que as crianças aprendam. Sem professor não é possível. Vamos lutar pelo concurso, mas até que ele aconteça vamos priorizar o professor na escola, nem que tenhamos que desacelerar os projetos". (S2)

“Fica claro que quando as escolas têm seus problemas de infraestrutura e pessoal mais equacionados, a discussão sobre os problemas pedagógicos ganha mais força. Temos que dar condição às escolas primeiro, e aí elas trabalham e o Ideb melhora". (S2)

Considerando que a fala oficial preserva as concepções de qualidade e de avaliação, destacamos a seguir, para efeito do acompanhamento das aprendizagens dos segmentos envolvidos na negociação, o significativo avanço de algumas unidades escolares na forma de conduzir o debate e apresentar seu processo interno de qualificação do projeto da escola. No primeiro encontro, as CPAs estavam aparentemente à vontade no processo, porém sua participação revelou-se submissa ao formato do encontro, que definia a ordem das falas em uma sequência linear e hierarquizada que dificultava a ocorrência da negociação (fala oficial, fala das CPAs, resposta oficial sem espaço ou tempo para réplica).

O segundo encontro, mesmo ocorrendo em momento de instabilidade política, encontrou os atores das escolas mais organizados. Preparados para a negociação com o poder público, trouxeram dados concretos de sua realidade, tornando-os públicos. Superando certo amadorismo do primeiro momento, revelavam apropriação processual do significado da negociação. Há visível melhora na forma de apresentação dos problemas. As escolas retomam o encontro de negociação anterior, lembrando demandas não atendidas pela SME - "Acordos não foram cumpridos. Temos olhado para nossas responsabilidades. Mas, sem professor, o que fazer?" - ou relatos que indicam estágios diferenciados das escolas na forma de compreender a política de AIP e o quanto esta tem ajudado a escola a progredir e a enfrentar seus problemas:

“Temos que melhorar a participação não apenas na CPA, mas na vida da escola, politizar a participação dos estudantes".

“O Ideb já foi objeto de conversa em nossa CPA, mas nosso foco é a rede e nossa escola".

“Tivemos a participação de um membro da CPA que sabia usar bem a tecnologia e ele fez vários gráficos com níveis de aprendizagem e isso ajuda a monitorar avanços". 
“Usamos os resultados da Prova Brasil mais para orientar professores e discutimos o planejamento a partir destes resultados. O Conselho de Classe faz uso formativo da avaliação".

"Tivemos algumas melhoras, pois houve o fim do intermediário, as quadras poliesportivas estão sendo cobertas. Agora precisamos de funcionários".

"Instituímos um caderno volante da equipe gestora".

"As condições da escola estão péssimas, afeta inclusive o trabalho da CPA".

"CPA tem seu papel diluído na vida da escola, não é algo centralizado, se dissemina pela escola. Ações político-pedagógicas são assumidas por todos. É uma construção".

Se a qualidade das intervenções melhorou no segundo encontro, merece destaque negativo a diminuição da voz dos segmentos dos não profissionais na negociação em contraste com o primeiro. A voz da CPA passou a ser mais marcada pelos profissionais da educação, observando-se em algumas realidades apagamento inclusive da voz do OP. Terá sido decorrência do entendimento de que a negociação com o poder central compete ao diretor? Cabe investigar se, nos processos internos de negociação ocorridos no nível das escolas, tais diretores igualmente se fazem presentes ou delegam a atividade sem maior constrangimento.

Observamos que remanesce a baixa participação dos representantes das famílias e dos funcionários nos encontros. A participação dos estudantes continua numericamente expressiva, embora no segundo encontro, cujo roteiro estava mais estruturado, houve CPAs que trouxeram os estudantes à frente, porém sem nenhum papel a cumprir, salvo o de acessórios do cenário. Tal característica não foi a marca do primeiro encontro, no qual os estudantes, de modo direto e objetivo, manifestavam-se:

"Senhor secretário, na minha escola a professora ensina a prevenir dengue. Mas o que explica a água que fica empoçada depois da chuva dias e dias? Estamos vendo focos de dengue na escola".

"Tem professor que falta muito. Isso nos prejudica, pois perdemos aulas ou vem professor substituto que não entende bem do assunto. Isso não parece certo, pois perdemos qualidade e o professor recebe o salário do mesmo jeito".

"Pelo andar da carruagem, estou entendendo que vou me formar e a quadra da escola vai continuar descoberta. A gente vai continuar torrando no sol".

Como avanço detectado no segundo encontro, podemos citar a decisão de inclusão de mais membros da SME no processo de negociação, ouvindo as demandas das escolas e sendo demandados pelo secretário objetivamente. À medida que o secretário pedia explicações destes setores para se posicionar na negociação, observou-se a fragmentação das ações, a precariedade dos registros, a frágil intersetorialidade de rede municipal e os entraves burocráticos que emperram os processos que poderiam ajudar o pedagógico a deslanchar. Problemas estes que remanesceram do primeiro encontro e que incomodam os coletivos das escolas, 
dada a recorrência dos mesmos ao longo dos tempos. Este aspecto arrefece a confiança dos atores na negociação.

Os planos de avaliação apresentados pelas CPAs são muito heterogêneos, mas já há socialização de formatos bastante didáticos com demandas explícitas para cada segmento e indicação de metas concretas. Houve aumento do olhar das CPAs para as questões pedagógicas, talvez pela indução propiciada pelo roteiro que norteou a apresentação das escolas. No entanto, os OPs deixam entrever que a discussão sobre qualidade tem ocorrido de forma mais consistente nas escolas, não se limitando às CPAs. A avaliação parece estar se tornando parte da vida das escolas e tem sido amplamente utilizada para iluminar o processo decisório, rumo à construção de uma escola pública de qualidade.

Se o Plano de Avaliação, como instrumento formal de registro das demandas das escolas e das respostas que elas obtêm ao longo do tempo, ainda deixa a desejar, tanto na forma como no conteúdo que veicula ao ser encaminhado oficialmente, vemos que no encontro de negociação a conversa sobre qualidade da escola pública ganha força. Vários aspectos ausentes nos Planos ganham espaço no debate público e permitem problematização. O diálogo sobre o compromisso dos atores com o pacto de qualidade negociado é intensificado e o engajamento com o projeto de melhoria parece mais viável.

Finalizando, as falas das CPAs nos dois encontros desfiam um conjunto de problemas que variam de complexidade, revelando as distintas condições de funcionamento das escolas na mesma rede de ensino. Há algumas que pleiteiam cobertura de sua quadra. Outras sequer possuem quadra ou mesmo espaço para a sua construção. Predominam problemas ligados à melhoria da infraestrutura, sobretudo dos laboratórios de informática: “Os computadores já chegaram. Agora falta espaço e/ou pessoal para ensinar a usar os equipamentos. Precisamos de monitores. Precisamos de parcerias com a iniciativa privada ou com as universidades", sugerem algumas CPAs. Surgem sérias críticas à falta de manutenção das escolas ou à demora/inexistência de um planejamento metódico que se antecipe àssuas demandas. Isso envolve desde a poda de árvores, a colocação de alambrados, a questão da falta de segurança das escolas. "Senhor secretário, o que o senhor pode fazer por nós?” aparece várias vezes na fala das crianças, que demandam desde a construção de muros para evitar que a bola suma, até a drenagem dos terrenos que acumulam água.

Os encontros de negociação revelam-se potentes para manter o projeto de AIP da rede municipal de Campinas vivo e robusto para enfrentar os processos de avaliação externa. A comunidade escolar, cada uma a seu modo, parece estar incorporando a proposta da AIP e assumindo algum protagonismo na cena da qualificação do projeto pedagógico. Especialmente as famílias celebram a possibilidade de 
dialogar diretamente com o poder central e ouvir as explicações que fragilizam a qualidade da escola de seus filhos. Este movimento denota algum enraizamento da AIP no chão das escolas, que resistem às intempéries que ocorrem no nível central. Isso ajuda a manter o tom da conversa entre atores do topo e da base em um nível de concepção de qualidade do ensino bem superior ao daquele induzido pelas políticas de responsabilização vertical.

\section{Considerações finais}

Tendo em vista que o processo de qualificação da escola pública é contínuo e inesgotável e que a implementação de políticas de avaliação contra-hegemônicas constitui uma opção desafiadora face aos princípios que defende, os quais contrastam com os interesses maiores do mercado, experiências como esta em desenvolvimento pela Secretaria Municipal de Educação de Campinas devem ser acompanhadas com interesse e investigadas para além do que dizem os documentos oficiais. Estes podem discorrer sobre pressupostos ou princípios filosóficos bastante pertinentes do ponto de vista da relevância social, sem que necessariamente dialoguem com o conjunto de ações que são implementadas para ajudar a política a se manter coerente com os princípios anunciados.

Cabe lembrar que a interpretação das contradições presentes em processos contrarregulatórios exige certa expertise dos leitores, sobretudo daqueles pretensamente críticos, que tendem a desprender o projeto das condições históricas que o constrangem. Esquecer desse cenário pode servir muito mais às forças conservadoras, despotencializando ações propositivas que não se contentam em ser apenas denunciadoras, mas que buscam oferecer-se como alternativas possíveis para alimentar a esperança de uma escola pública de qualidade. Isso posto, entender os limites, explicitar as fragilidades e apontar sugestões, objetivando o aprimoramento da proposta e a manutenção de sua coerência ético-epistemológica, devem constituir-se bandeira de todos que defendem a formatividade da avaliação e que não desconhecem os interesses que disputam palmo a palmo o campo.

A AIP se reveste de grande valor à organização do trabalho escolar existente pela capacidade que vem demonstrando de recriar o desejo do encontro entre segmentos, quase sempre dispersos na forma de ação, ainda que algumas vezes coesos na imagem de futuro que possuem do que seja uma escola pública de qualidade. Ao se perceberem como coletivos organizados, passam a aprender a arte da negociação, movidos pela noção do bem comum e não por interesses corporativistas.

Os princípios da continuidade, da historicidade, devem ser considerados na meta-avaliação de projetos de avaliação que exercitam formas alternativas de responsabilização. Isso implicará admitir que o ritmo dos avanços precisa ser entendido 
e negociado sob pena de produzir desapontamentos e desistência ingênua dos atores. O que não deve ser objeto de negociação são os princípios que regem os modelos contra-hegemônicos de avaliação, especialmente porque estes traduzem concepções de qualidade, concepções de educação, de Homem e de mundo bastante distintivas. Se os modelos de avaliação externa, nacionais ou internacionais, não conseguem ou não desejam dar conta destas concepções mais ampliadas e socialmente relevantes, nem por isso podemos desprezá-las. Se o fizermos, correremos o risco de lastimar, muito em breve, a qualidade educacional que ajudamos a induzir, referendando formatos de avaliação reducionistas e excludentes ocultados pelo uso de tecnologias de medidas cada dia mais avançadas.

\section{Referências}

ÂNGULO, F.R.O planejamento da qualificação da escola: o leigo graal da mudança educacional. In: MURILLO, F.J. et al. A qualificação da escola: um novo enfoque. Porto Alegre: Artmed, 2007.

BARROSO, J. Regulação e desregulação nas políticas educativas: tendências emergentes em estudos de educação comparada. In: BARROSO, J. (Org.). A escola pública, regulação, desregulação e privatização. Porto: ASA, 2003. p. 19-48.

BAUMAN, Z. Em busca da política. Rio de Janeiro: Zahar, 2000.

BONDIOLLI, A. O projeto pedagógico da creche e a sua avaliação: a qualidade negociada. Campinas: Autores Associados, 2004.

BRYK, A.S.; SCHENEIDER, B. Trust in schools: a core resource for improvement. New York: Russell Sage Foundation, 2002.

CECCIN, R.B. "Recursos humanos em saúde", leia-se "Coletivos organizados de produção em saúde": desafios para a educação. In: PINHEIRO, R.; MATTOS, R.A. (Org.). Construção social da demanda: direito à saúde, trabalho em equipe, participação e espaços públicos. Rio de Janeiro: IMS/Uerj; Cepesc-Abrasco,2005. p. 161-180.

DIAS SOBRINHO, J. Avaliação e transformações da educação superior brasileira (1995-2009): do Provão ao Sinaes. Avaliação, Campinas; Sorocaba, SP, v. 15, n. 1, p. 195-224, mar. 2010.

FERNANDES, D. Avaliação externa: exames e estudos internacionais In: FERNANDES, D. Avaliar para aprender: fundamentos, práticas e políticas. São Paulo: Unesp, 2009.

FREITAS, L.C. Eliminação adiada: o ocaso das classes populares no interior da escola e a ocultação da (má) qualidade do ensino. Educação $\mathcal{E}$ Sociedade, Campinas, v. 28, n. 100, p. 965-987, 2007. 
FREITAS, L.C. et al. Avaliação educacional: caminhando pela contramão. Rio de Janeiro: Vozes, 2009.

FREITAS, L.C. Os reformadores empresariais da educação: a consolidação do neotecnicismo no Brasil. In: FONTOURA, H.A (Org.). Politicas públicas, movimentos sociais: desafios à Pós-graduação em Educação em suas múltiplas dimensões. Rio de Janeiro: ANPEd Nacional, 2011. p. 72-90.

FULLAN, M. O significado da mudança educacional. 4. ed. Porto Alegre: Artmed, 2009.

MADAUS, G.; RUSSELL, M.; HIGGINS, J. The paradoxe of high-stakes testing: how they affect students, their parents, teachers, principals, schools and society. Charlotte, NC: IAP, 2009.

MEHRY, E. Engravidando palavras: o caso da integralidade. In: PINHEIRO, R.; MATTOS, R.A. Construção social da demanda: direito à saúde, trabalho em equipe, participação e espaços públicos. Rio de Janeiro: IMS/Uerj; Cepesc-Abrasco, 2005. p. 195-206.

PARO, V.H. Progressão continuada, supervisão escolar e avaliação externa: implicações para a qualidade do ensino. Revista Brasileira de Educação, Rio de Janeiro; Campinas, v. 16, n. 48, p. 695-716, set./dez. 2011.

SORDI, M.R.L. A qualidade negociada como possibilidade de reinvenção de processos regulatórios: uma leitura da experiência das escolas da Rede Municipal de Campinas. In: SEMINÁRIO DE EDUCAÇÃO BRASILEIRA, 2., 2009, Campinas. Anais... Campinas, 2009.

SORDI, M.R.L.; SOUZA, E. A avaliação institucional como instância mediadora da qualidade da escola pública: a Rede Municipal de Educação de Campinas como espaço de aprendizagem. Campinas: Millenium, 2009.

SIMÕES, G.M.J. A auto-avaliação das escolas e a regulação da acção pública em educação. Sísifo, Revista de Ciências da Educação, Lisboa, n. 4, p. 39-48, 2007. Disponível em: <http://sisifo.fpce.ul>. Acesso em: dez. 2009.

Recebido em 10 de maio de 2012.

Aprovado em 1ํ de junho de 2012. 